\title{
DESIGN SCOPE AND LEVEL FOR STANDARD DESIGN CERTIFICATION UNDER A TWO STEP LICENSING PROCESS
}

\author{
NAMDUK SUH* and CHANGWOOK HUH \\ Korea Institute of Nuclear Safety \\ 62 Gwahak-Ro, Yusung-gu, Daejon, 305-338, Republic of Korea \\ *Corresponding author. E-mail : k220snd@kins.re.kr \\ Received June 05, 2011 \\ Accepted for Publication September 16, 2011
}

A small integral reactor SMART (System Integrated Modular Advanced ReacTor), being developed in Korea since late 1990s and targeted to obtaining a standard design approval by the end of 2011, is introduced. The design scope and level for design certification (DC) is well described in the U.S. NRC SECY documents published the early 1990s. However, the documents are valid for a one-step licensing process called a combined operating license (COL) by the U.S. NRC, while Korea still uses a two-step licensing process. Thus, referencing the concept of the SECY documents, we have established the design scope and level for the SMART DC using the contexts of the standard review plan (SRP). Some examples of the results and issues raised during our review are briefly presented in this paper. The same methodology will be applied to other types of reactor under development in Korea, such as future VHTR reactors.

KEYWORDS : Design Level, Design Scope, Design Certification, COL, Two Step Licensing Process

\section{INTRODUCTION}

In Korea, a small-to-medium sized integral type reactor, called the "System integrated Modular Advanced ReacTor (SMART)", has been under development since the late 1990s by the Korea Atomic Energy Research Institute (KAERI). The reactor can be used in such areas as seawater desalination and district heating. The KAERI plans to obtain Standard Design Approval (SDA) by the end of 2011. SMART aims at achieving enhanced safety and improved economy. The enhancement of safety and reliability is realized by incorporating inherent safetyimproving features and reliable passive safety systems, while the improvement in the economy is achieved through system simplification, component modularization, reduction of construction time, and high plant availability. The design characteristics contributing to the safety of SMART, which is a small integral type PWR with a rated thermal power of 330MWt, are inherent safety features, such as the integral configuration of the reactor coolant system and an improved natural circulation capability. By introducing a passive residual heat removal system and an advanced LOCA mitigation system, significant safety enhancement is achieved.

Determining in advance the design scope and level needed for SDA is important for successful licensing.
The KAERI has provided a draft table of the design scope and level referencing the U.S. NRC documents SECY-90-241 ${ }^{(1)}$ and SECY-90-377 ${ }^{(2)}$. The SECY documents are the only ones available that approach the design scope and level systematically. However, the referenced documents and the definitions in them concerning the design scope and level for SDA are valid for a one-step licensing process called $\mathrm{COL}^{(3)}$ of the U.S. NRC. If in the future a particular U.S. utility would try to apply for design certification to obtain a license under 10 CFR 50, which defines a two-step licensing process, the U.S. NRC would need to develop new reports to define the design scope and level under 10 CFR 50, but to date this has not been done. The DC process was remained in Korea for a potential licensee to have the option of engaging the regulatory body in early discussion through a preapplication process.

According to Fig. A-1-4 of SECY-90-377, licensing is completed almost at the time of design certification except for some site specific issues. Korea still uses a two-step licensing process, which means that even when the industry gets the SDA, they must also submit either a preliminary safety analysis report (PSAR) or a final safety analysis report (FSAR) to get a construction permit (CP) and an operation license (OL), respectively. The DC process was introduced in Korea to change the two-step 
licensing process of Korea to a COL process. However, later discussion showed that the one-step licensing process is not advantageous in Korea, so the shift to a COL process was suspended and the DC process remained in the regulatory process. Now, for the DC, the Korean designer intends to engage the regulatory body in the discussion in the early phase of the design as a pre-application process and the regulatory body is expected to provide safety requirements early. Because developing a new reactor needs a big financial investment and the effects are huge if the design fails to get a licensing, the Korean government also agreed to this concept of design certification, even though it has not been officially stipulated. Thus, the methodology defined in this paper is also applicable for future types of reactor under development in Korea, such as very high temperature gas-cooled reactors (VHTRs).

These differences in the licensing process between Korea and the U.S., and of the concept of DC in Korea made it necessary to newly define the design scope and level of DC for SMART. The conclusion reached might not be far from the definitions described in the SECY documents. In the language of the SECY documents, the Level 3 Tier 1 design seems sufficient under our two-step licensing process, at least theoretically, for our SMART DC. Furthermore, this definition is expressed in other formats using the contexts of the SRP. The conclusion has been reached through discussions with the designer and this paper presents briefly how it was reached.

Section 2 introduces the main features of SMART systems including the verification test plan for the design. The description of the system characteristics is needed to understand the SMART design. Section 3 summarizes the concept of design scope and level defined in the SECY documents. Section 4 presents what was developed concerning the scope and level of design for SMART DC expressed in SRP formats and Section 5 concludes.

\section{OVERVIEW OF SMART SYSTEMS}

\subsection{Overview}

The SMART design incorporates new components and system features and the main design features are summarized in the following ${ }^{(4,5,6)}$.

The low power density design with about a $5 \mathrm{w} / \mathrm{o} \mathrm{UO}_{2}$ fueled core has been proven to provide a thermal margin of more than $15 \%$ to accommodate any design basis transients with regard to the critical heat flux. This feature ensures the core thermal reliability under normal operation and any design bases events. Core reactivity control during normal operation is achieved by control rods and soluble boron. Burnable poison rods are introduced for the flat radial and axial power profiles, which result in an increased thermal margin in the core. By having a nearly constant reactor coolant average temperature program in the reactor, the regulating system improves the load follow performance in view of a stable pressure and water level within the pressurizer.

A single reactor pressure vessel contains the major primary components, such as a pressurizer, steam generators and reactor coolant pumps, as is depicted in Fig. 1. The integrated arrangement of the reactor vessel assembly enables the large size pipe connections to be removed, which results in elimination of a large break loss of coolant accidents. The in-vessel pressurizer is designed to control the system pressure at nearly a constant level during all design bases events. The modular type once-through steam generator cassette consists of helically coiled heat transfer tubes to produce $30^{\circ} \mathrm{C}$ superheated steam in normal operating conditions. A small inventory of the steam generator secondary side water prohibits a return-to-power following a steam line break accident.

Other improved design features include the canned motor reactor coolant pump which has no pump seals and thus the loss of coolant associated with pump seal failure is prevented. Four channel control rod position indicators contribute to the simplification of the core protection system and to the enhancement of the system's reliability. Furthermore, an advanced man-machine interface system using digital techniques and equipment reduces the human error factors, and consequently improves the plant's reliability.

Engineered safety systems designed to function automatically on demand consists of a reactor shutdown system, safety injection system, passive residual heat removal system, shutdown cooling system, and a containment spray system. Additional safety systems include a reactor overpressure protection system and a severe accident mitigation system. Under any circumstances, the reactor can be shut down by inserting control rods or injecting boron. A passive residual heat removal system prevents over-heating and over-pressurization of the primary system in the case of emergency events. It removes the decay and sensible heat by the natural circulation of a two-phase fluid. The core is maintained undamaged for 36 hours without corrective action by the operator. The reactor

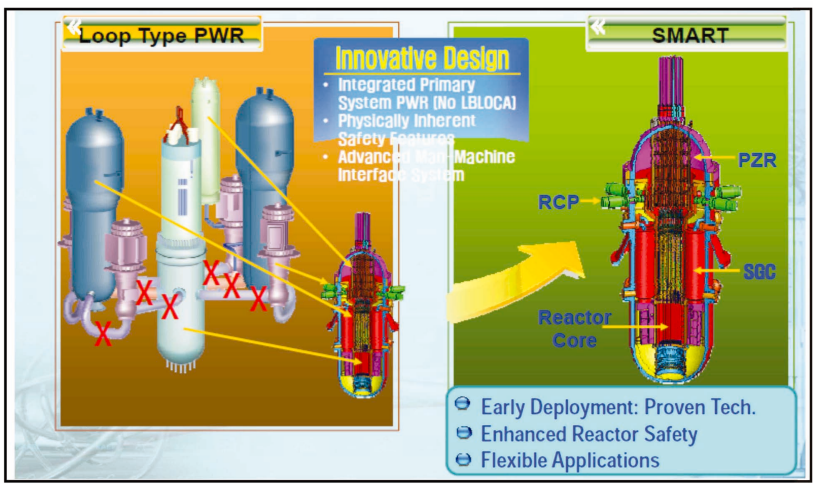

Fig. 1. Integral Structure of SMART 
overpressure during any design bases events can be reduced by opening the pressurizer safety valve.

A more detailed description of the SMART nuclear systems is summarized in the following sections.

\subsection{Description of the Nuclear Systems 2.2.1 Reactor Vessel Assembly}

The reactor assembly of a SMART contains its major primary systems, such as fuel and the core, eight steam generators, a pressurizer, four reactor coolant pumps, and twenty-five control rod drive mechanisms, in a single pressurized reactor vessel. The integrated arrangement of these components enables the removal of the large pipe connections between major reactor coolant systems, and thus fundamentally eliminates the possibility of large break loss of coolant accidents (LBLOCAs). This feature, in turn, becomes a contributing factor for the safety enhancement of a SMART. The reactor coolant forced by RCPs installed horizontally at the upper shell of the RPV flows upward through the core, and enters the shell side of the SG from the top of the SG. The secondary side feedwater enters the helically coiled tube side from the bottom of the SG and flows upward to remove the heat from the shell side eventually exiting the SG in a superheated steam condition. The large free volume in the top part of the RPV located above the reactor water level is used as a PZR region. As the steam volume of a PZR is designed to be sufficiently large, a spray is not required for a load maneuvering operation. Eight SGs are located at the circumferential periphery with an equal spacing inside of the RPV and relatively high above the core to provide a driving force for a natural circulation of the coolant.

\subsubsection{Fuel Assembly}

The SMART core is composed of 57 fuel assemblies, the design and performance of which are based on the proven $17 \times 17$ array with $\mathrm{UO}_{2}$ ceramic fuel rods in the commercial PWRs. Each fuel assembly holds 264 fuel rods, a twenty-four guide tube for control rods, and one instrumentation thimble which are mechanically joined in a square array. A total of eight space grids hold the fuel rods in their specified positions. Top and bottom space grids are made of inconel, and zircaloy is used for the space grids.

\subsubsection{Steam Generator Cassette}

SMART has eight identical SG cassettes that are located on the annulus formed by the RPV and the core support barrel (CSB). The SG cassettes have a oncethrough design with a number of helically coiled tubes. The primary reactor coolant flows downward in the shell side of the SG tubes, while the secondary feedwater flows upward through the inside of the tube. In the case of an abnormal shutdown of the reactor, the SG is used as the heat exchanger for the passive residual heat removal system (PRHRS), which permits an independent operation of the PRHRS from the hydraulic condition of the primary system. Each SG cassette contains about 375 tubes with orifices for the prevention of a flow instability.

\subsubsection{Reactor Coolant Pump}

The SMART RCP is a canned motor pump that does not require pump seals. This characteristic basically eliminates an SBLOCA associated with a pump seal failure, which is one of the design bases events (DBEs) for conventional reactors. SMART has four RCPs horizontally installed on the upper shell of the RPV. Each RCP is an integral unit consisting of a canned asynchronous three phase motor and an axial-flow, single-stage pump. The motor rotor and the impeller shaft are connected by a common shaft rotating on two radial bearings and one axial thrust bearing, which uses a specialized graphitebased material. The cooling of the motor is accomplished by component cooling water that flows through the tubes wound helically along the outer surface of the motor stator. The rotational speed of the pump rotor is measured by a sensor installed in the upper part of the motor.

\subsection{SMART Safety and Related Systems}

The safety approach for a SMART is based on a defense-in-depth concept with extensive use of inherent safety features and passive engineered safety systems combined with proven active system. Inherent safety features incorporated into the SMART design enhance the accident resistance of a SMART. The SMART contains the major primary components, such as a core, eight SGs, a pressurizer, four reactor coolant pumps, and twenty-five control rod drive mechanisms in a single reactor pressure vessel. The integral arrangement of the primary system removes the large pipe connections between the major components and thus, fundamentally eliminates the possibility of a LBLOCA. The canned motor RCP eliminates the need for an RCP seal, and basically eliminates the potential for an SBLOCA associated with a seal failure. The modular type once-through steam generators are located relatively high above the core to provide a driving force for natural circulation flow. This design feature along with low flow resistance enables the system to have residual heat removal with a natural circulation when normal means to transfer residual heat from the core are not available. A large volume of semi-passive PZR can accommodate a wide range of pressure transients during system transients and accidents. Low core power density lowers the fuel element temperature rise under accident conditions and increases the thermal margin. A negative moderator temperature coefficient yields beneficial effects on a core self stabilization, and limits the reactor power during accidents.

Besides the inherent safety characteristics of a SMART, further enhanced safety is accomplished with highly reliable 
engineered safety systems. The engineered safety systems are designed to function automatically on demand; they consist of a reactor shutdown system and a passive residual heat removal system, a shutdown cooling system and a containment spray system. The schematic diagram of SMART safety systems are depicted in Fig. 2. Additional engineered safety systems include a reactor overpressure protection system and a severe accident mitigation system.

\section{Reactor Shutdown System (RSS)}

The reactor shutdown system initiates a reliable and rapid shutdown if the monitored variables deviate from the permissible operating range to the degree that a safety limit may be breached. The reactor shutdown consists of control rods that absorb neutrons inside a core and a control rod drive mechanism (CRDM). The shutdown signal de-energizes the CRDM and then the control rods drop into the reactor core by the force of gravity and immediately stop the neutron chain reactions.

\section{Safety Injection System (SIS)}

The SIS is provided to prevent core damage during an SBLOCA. The core is protected during an SBLOCA and covered by a large primary coolant inventory. When the pressure drops below $10 \mathrm{MPa}$ in the PZR, the SIS is actuated automatically and cold water from IRWST is injected immediately into the reactor coolant system. The SIS consists of four independent trains with a $100 \%$ capacity for each train. The system provides a vessel refilling so that the decay heat removal system can function properly in a long-term recovery mode following an accident.

\section{Passive Residual Heat Removal System (PRHRS)}

The PRHRS passively removes the core decay heat and sensible heat by a natural circulation in the case of an emergency such as the unavailability of feedwater supply or a station blackout. In addition, the PRHRS may also be used in long-term cooling for a repair or refueling. The PRHRS consists of four independent trains with $50 \%$ capacity each. Two trains are sufficient to remove the

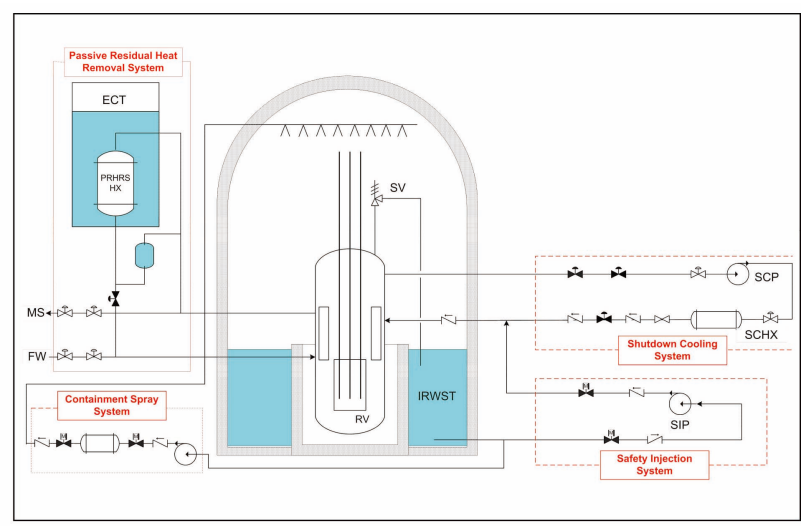

Fig. 2. Schematic Diagram of SMART Safety Systems decay heat. Each train is composed of an emergency cooldown tank, a heat exchanger and a makeup tank. The system is cooled by cool-down water or by air when the cool-down tank is dried out. The system is designed to maintain the core undamaged for 36 hours without any corrective actions by operators for the postulated design basis accidents. In the case of a normal shutdown of a SMART, the residual heat is removed through the steam generators to the condenser with a turbine bypass system.

\subsection{Thermal-hydraulic Test}

Existing proven PWR technologies are used for the SMART design. However, it also adopts new and innovative design features and technologies that must be proven through tests, experiments, analyses, and/or the verification of design methods. A series of fundamental tests and experiments were carried out throughout the SMART development phases to examine the physical phenomena related to the specific SMART design concepts. The main purpose of these experiments was two-fold: to understand the thermal-hydraulic behaviour of the specific design concepts and to obtain fundamental data to be used, in turn, for further feedback to the optimization of design. Among the experiments conducted, specific SMART design-related experiments are as follows:

- Boiling heat transfer characteristics in the helically coiled steam generator tube,

- Experiment for natural circulation in the integral arrangement of the reactor system,

- Two-phase critical flow tests with non-condensable gases to investigate the thermal-hydraulic phenomena of critical flow with the existence of non-condensable gases,

- Critical heat flux measurement for SMART-specific $\mathrm{UO}_{2}$ fuel rod bundles,

- Experiments on the phenomena and characteristics of heat transfer through the condensing mechanism of the heat exchanger inside PRHRS tanks.

Described below are brief introductions to the typical tests and experiments implemented to verify the SMART design characteristic.

\subsubsection{Two-Phase Critical Flow Test with a Non- Condensable Gas}

The early SMART concept adopted an in-vessel pressurizer type with an inherent self-pressure regulating capability designed to operate via the thermo-pneumatic balance between the water, steam, and nitrogen gas, which are the three fluids that fill the pressurizer. In the event of a rupture of a pipe line connected to the pressurizer at a high-system pressure, a mixture of water, steam, and nitrogen is discharged through the break at critical flow conditions. The computer codes for the safety analysis of a SMART need to use a verified and validated model for 
this critical flow. To investigate the thermal-hydraulic phenomena of the critical flow affected by the noncondensable break flow, a separate effects test facility was designed and installed at the KAERI site. The test data from the facility was used for developing and verifying the critical break flow model for SMART.

\subsubsection{Integral Effect Test}

An experimental verification by an Integral Simulation for a Transient and Accident (VISTA) facility has been constructed to simulate the various transient and events of an integral reactor. The VISTA facility has been used to understand the thermal-hydraulic behaviour including several operational transients and design basis accidents. During the past five years, several integral effect tests have been carried out and reported, including performance tests, RCP transients, power transients and heat-up or cooldown procedures, and safety related design basis accidents.

\subsubsection{Major Components Performance Test}

A performance test of the major components, such as the RCP, SG, and CRDM, was carried out. In the SMART SDA Program, additional performance tests for the RCP and CRDM are scheduled to be performed to verify the final design models.

\section{DESIGN SCOPE AND LEVEL FOR DESIGN CERTIFICATION UNDER 10 CFR 52 OF U.S. NRC}

In May 1989 the U.S. NRC issued a new rule, 10 CFR 52 , that provided for early site permits, certified standard designs, and combined construction permits and operating licenses. This new rule made a one-step licensing process possible, which was a change from the previous two-step licensing process of 10 CFR 50.

The issue of the level of detail required by Part 52 is presented in the SECY-90-241. The levels are classified into four levels and in this section the definitions of the four levels described in the SECY report are briefly summarized.

\subsection{Four Levels of Detail for Design Certification}

Level 1: The degree of standardization resulting from this level of detail and the certification process will provide identical physical, functional, and performance characteristics for all structures, systems and components except for site specific characteristics. This level can be re-phrased to include procurement specifications as well as construction and installation specifications for all structures, systems, and components except for site-specific details. However, the Level 1 status of design may exceed the requirements of Part 52. This Level 1 is similar to that level of the final safety analysis report (FSAR) at the operating license $(\mathrm{OL})$ stage.

Level 2: The degree of standardization resulting from this level of detail and the certification process will provide physically similar, and identical functional and performance characteristics of all structures, systems, and components affecting safety, except for site specific characteristics. This level can be re-phrased to finalize procurement specifications and construction and installation specifications for all structures, systems, and components affecting safety. This differs from the Level 1 option, which requires the same detail for all systems as well as exact physical location, configuration, and orientation of components and supports. In other words, for all pumps on systems affecting safety, the type, pumping capacity and head, and certain general physical attributes will be specified; but the exact locations of the inlet and outlet nozzles, exact weight, and mounting/supporting details will not be supplied.

Level 3: The degree of standardization resulting from this level of detail and the certification process will provide identical functional and performance characteristics of all systems, structures, and components, except for sitespecific characteristics. This level includes information necessary to permit the preparation of procurement specifications as well as construction and installation specifications for structures, systems, and components affecting safety. Unlike the Level 2 option where it is expected to have information (physical characteristics) for all components on systems affecting safety, in the Level 3 approach, the performance characteristics of the major components for systems affecting safety is expected to be provided. This is proposed by industry in conjunction with a two-tiered concept. Tier 1 information will be certified by the rule-making process and will not be changed without previous NRC approval and contains an independent description of the design and design bases, and inspection, test, analysis, and acceptance criteria (ITAAC). Tier 2 will include information demonstrating how Tier 1 criteria are implemented in the design and will be of sufficient detail for the staff to make its safety determination as to the adequacy of the design as described in Tier 1 and should not undergo any changes before COL without previous NRC approval.

Level 4: This level provides identical functional characteristics for selected safety-related and risksignificant structures, systems, and components. This level represents a conceptual design stage, so Level 4 is not an adequate level for design certification under Part 52.

\subsection{Design Scope for Certification under 10 CFR 52}

Regarding the scope of an application for design certification, Part 52 states that, with some exceptions for reactors of advanced design, "Any person may seek a standard design certification for an essentially complete nuclear power plant design...." An essentially complete 


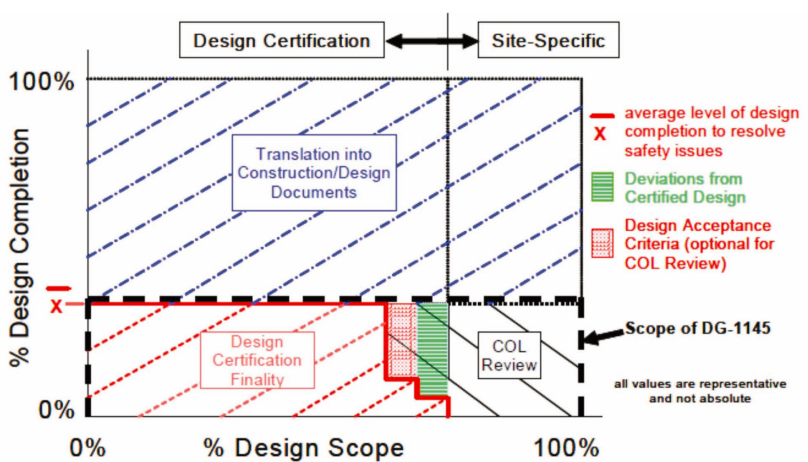

Fig. 3. Design Scope for COL (from Regulatory Guide 1.206)

design includes all structures, systems, and components which can affect safe operation of the plant except for site-specific elements such as the service water intake structure and the ultimate heat sink." Approximate quantification of the design scope is said to be 70-80\% of the total system. This is clearly depicted in Fig. 1 of Regulatory Guide 1.206 (3), "Combined License Applications for Nuclear Power Plants," which is as shown in Fig. 3.

\section{DESIGN SCOPE AND LEVEL FOR SMART DESIGN CERTIFICATION}

In Section III, the SECY documents on the design scope and level for standard design certification of U.S. NRC were analyzed because they are the only systematic approach known for this issue. It was clearly mentioned in the documents that Level 2, which is required under COL licensing process for safety systems, is equivalent to the level of FSAR under two-step licensing process, except for site specific features.

Since Korea still maintains the two-step licensing process, the levels required under the one-step COL licensing process certainly should not be asked for. Thus KINS (Korea Institute of Nuclear Safety) started to discuss this issue of defining design scope and level for DC with the SMART NSSS designer KAERI at the end of December 2008. In discussions with the BOP designer, it was also found that the terminologies like Level 2, component procurement specification etc., which are the basic terms consistently used in the SECY documents, are not understood in the same way between the staffs of different organizations in Korea.

One example of Level 2 for pump taken in the SECY-90-377 is that, at the time of design certification, the designer should know the pump type (e.g., centrifugal or positive displacement), the pump flow, the shape of the pump head curve (e.g., continuously decreasing), the approximate shutoff head and net positive suction head
(NPSH) requirements, the approximate motor horsepower and amperes, the pump style (e.g., close-coupled with end suction and top discharge or vertical in-line) and the size and approximate location of the pump nozzles.

However, what should be required for Level 3 of the same pump was not described. Furthermore, how to specify the requirement "the level of detail must permit NRC to reach a final conclusion on all safety questions associated with the design before certification" for the nuclear design, for example, of SSAR section 4.3, is not clear and it is understood differently by different organizations.

This shows clearly that even the NRC approach is systematic and clear, but in some ways, it still is difficult to apply the approach directly in different countries, under different licensing framework, and for different reactor types other than the current light water reactors. Thus, the design scope and level needs to be established case by case in different countries, reflecting the specific regulatory environment.

Evaluating the SECY document, it was understood that, theoretically, the Level 3 is sufficient for our SMART under the two-step licensing process except for certain safety systems essential to ascertain the safety of the reactor, and the designer expects that much of the system can be designed to Level 2.

On the other hand, it was still quite hard to have a common understanding of what Level 2 and Level 3 mean for the design of all the other systems. In other words, it was necessary to have a common and more easy to understand language defining the design level. This was asked for, because taking into account the tight schedule planned for the licensing review, not much time to discuss this issue of design scope and level would be available once the official licensing process gets started. Thus it was very important to establish a scope and to have a common understanding regarding the issue.

After discussions between the KINS staffs and the designer, we decided that it was much better to define the design level in the format of an SRP (Standard Review Plan) while keeping the contexts of levels defined in the SECY documents. The current SRP contains all the information needed for the regulatory review to ascertain safety. Taking an example of Chapter 4.3 nuclear design, in the SECY documents it was not quite clear what should be the Level 2 design for the reactor core and thermal design, but SRP clearly defines what should be provided, what kind of correlations should be used, etc. On the other hand, the SECY documents define more clearly the levels for some mechanical components like pumps or pipes so we concluded that the best way to define design scope and level basically should be based on the SRP and then complement it with the contexts of SECY reports for some nuclear island designs. For a system the designer claims to design to Level 3, the contents were reviewed and the relevant parts of SRP were removed from DC in case it is agreed with the designer. 
Table 1. Design Level for SRP Section 4.3

\begin{tabular}{|c|c|c|c|}
\hline SSAR Chapter & Areas of Review & What to Provide in SSAR & Design Level \\
\hline 4.3 Nuclear Design & $\begin{array}{l}\text { Nuclear Design of the fuel assem- } \\
\text { blies, control systems, and reactor } \\
\text { core will be reviewed to confirm } \\
\text { that fuel design limits will not be } \\
\text { exceeded during normal operation } \\
\text { or anticipated operational transients } \\
\text { and that the effects of postulated } \\
\text { reactivity accidents will not cause } \\
\text { significant damage to the reactor } \\
\text { coolant pressure boundary or impair } \\
\text { the capability to cool the core. }\end{array}$ & $\begin{array}{l}\text { - } \text { design bases } \\
\text { - core power distribution used in } \\
\text { safety analyses } \\
\text { - reactivity coefficients used in } \\
\text { safety analyses } \\
\text { - reactivity control systems and } \\
\text { CVCS } \\
\text { - control rod patterns and reactivity } \\
\text { worths } \\
\text { - stability } \\
\text { - pressure vessel irradiation } \\
\text { - analyses code systems and veri- } \\
\text { fication }\end{array}$ & $\begin{array}{l}\text { - designed to Level } 2 \\
\text { - to provide informations pursuant } \\
\text { to SRP }\end{array}$ \\
\hline
\end{tabular}

Table 2. Design Level of SRP Section 19.2

\begin{tabular}{|c|c|c|c|}
\hline SSAR Chapter & Areas of Review & What to Provide in SSAR & Design Level \\
\hline $\begin{array}{l}\text { 19.2 Severe } \\
\text { Accident and } \\
\text { Containment } \\
\text { Performance }\end{array}$ & $\begin{array}{l}\text { - } \mathrm{H}_{2} \text { production and control } \\
\text { - rapid depressurization of RCS } \\
\text { - mitigation of DCH } \\
\text { - ex-vessel coolability of coriumn } \\
\text { - in-vessel retention of corium } \\
\text { - steam explosion } \\
\text { - containment overpressure } \\
\text { - equipment survivability } \\
\text { - containment performance }\end{array}$ & $\begin{array}{l}\text { - } \mathrm{H}_{2} \text { production and control } \\
\text { - consider in- and out-vessel } \\
\text { hydrogen production } \\
\text { - } \mathrm{H}_{2} \text { control by PAR and Igniter } \\
\text { - Evaluation of containment load } \\
\text { and explosion load assuming } \\
\text { complete } \mathrm{H}_{2} \text { burn } \\
\text { - rapid depressurization of RCS } \\
\text { - depressurization capability at } \\
\text { TLOFW } \\
\text { - mitigation of DCH } \\
\text { - probabilistic and deterministic } \\
\text { evaluation of DCH load } \\
\text { - ex-vessel coolability of corium } \\
\text { - show integrity of containment } \\
\text { liner for } 24 \text { hrs } \\
\text { - in-vessel retention of corium } \\
\text { - evaluation of IVR capability } \\
\text { - steam explosion } \\
\text { - evalution of in- and out-vessel } \\
\text { steam explosion and spike effect } \\
\text { - containment overpressure } \\
\text { - FLC is satisfied for } 24 \text { hrs. }\end{array}$ & $\begin{array}{l}\text { - designed basically to Level } 3 \\
\text { - mid-loop operation will not be } \\
\text { evaluated } \\
\text { - equipment survivability under } \\
\text { SA condition will be evaluated } \\
\text { on } 2011 \\
\text { - analysis showing the fission } \\
\text { product release after } 24 \text { hrs can } \\
\text { be controlled }\end{array}$ \\
\hline
\end{tabular}

An example of designing to Level 2 for the nuclear design of SSAR section 4.3 is given. The simplified format available is given in Table 1. It is a summary of the current SRP because nuclear design is such a well established area and the designer will have no difficulties in designing to Level 2. Areas of review are the objective of the SRP section 4.3. The contents to provide in the design are the level the designer is going to provide in section 4.3 to Level 2. One example of designing to Level 3 comes from the design against severe accident and it is given in Table 2 .

The above table is made for all the 19 chapters, to 3digit sections, of the SRP discussing with the designer.

Some 3-digit sections of SRP will be removed in the SSAR description because it is understood to be out of the scope of the design certification. Typical sections come 
from the rad-waste systems. Thus the scope for design certification is estimated to be around $80 \%$ of the total system and no concerns regarding the scope of the design were made.

It is hoped this pre-establishment of design scope and level will make the licensing process more efficient, given the tight review schedule planned. This kind of approach needs to be developed and refined further to be used for other type of reactors, including Gen IV reactors under development in Korea.

\section{CONCLUSIONS}

A small-sized integral reactor SMART is under development in Korea, to obtain a standard design approval by the end of 2011. A brief system description including the inherent safety characteristics and designed-in-safety features is given. One of the major regulatory activities to prepare for the licensing of SMART was to establish the design scope and level of DC. The U.S. NRC approach was evaluated and it was found that basically Level 3 is enough for the design certification under the two-step licensing process, but discussion with the designer confirmed that safety important systems are required to be designed to Level 2. The developed design scope and level was based on SRP contexts and it was complemented by the SECY concepts. We believe this format contributes to a common understanding between the different organizations. Brief results are presented in this paper. The same methodology could be used in defining the design scope and level for other types of reactors under development, such as VHTRs.

\section{NOMENCLATURE \\ APR1400 - Advanced Power Reactor 1400 \\ BOP - Balance of Plant \\ CRDM - Control Rod Drive Mechanism}

$\begin{array}{ll}\text { COL } & \text { - Combined Operating License } \\ \text { DBE } & - \text { Design Basis Event } \\ \text { DC } & - \text { Design Certification } \\ \text { ITAAC } & - \text { Inspection, Test, Analysis, and Acceptance } \\ & \text { Criteria } \\ \text { KAERI } & - \text { Korea Atomic Energy Research Institute } \\ \text { KINS } & - \text { Korea Institute of Nuclear Safety } \\ \text { NSSS } & - \text { Nuclear Steam Supply System } \\ \text { PAR } & - \text { Passive Autocatalytic Recombiner } \\ \text { PRHRS } & - \text { Passive Residual Heat Removal System } \\ \text { PZR } & - \text { Pressurizer } \\ \text { RCP } & - \text { Reactor Coolant Pump } \\ \text { RCS } & - \text { Reactor Coolant System } \\ \text { RPV } & - \text { Reactor Pressure Vessel } \\ \text { RSS } & - \text { Reactor Shutdown System } \\ \text { SDA } & - \text { Standard Design Approval } \\ \text { SG } & - \text { Steam Generator } \\ \text { SIS } & - \text { Safety Injection System } \\ \text { SMART } & - \text { System integrated Modular Advanced } \\ & \text { ReacTor } \\ \text { SSAR } & - \text { Standard Safety Analysis Report } \\ \text { VISTA } & - \text { Verification by an Integral Simulation for a } \\ & \text { Transient and Accident } \\ & \end{array}$

\section{REFERENCES}

[1] SECY-90-241, "Level of Detail Required for Design Certification under Part 52", U.S. NRC, July, 1990

[2] SECY-90-377, "Requirements for Design Certification under 10CFR Part 52”, U.S. NRC, November, 1990

[ 3 ] Regulatory Guide 1.206, "Combined License Applications for Nuclear Power Plants", U.S. NRC, June, 2007

[4] Korea Atomic Energy Research Institute, "SMART Top Tier Requirements", 2009.5.

[5] Korea Atomic Energy Research Institute, "Development of a Phenomena Identification and Ranking Table (PIRT) of Thermal Hydraulic Phenomena for SMART", 2009.6.

[6] Korea Atomic Energy Research Institute, "SMART NSSS Design Bases", 2009.7. 